Environment, Biodiversity \& Soil Security
(EBSS)
http://jenvbs.journals.ekb.eg//

\title{
Biochemical Assessments of some Important Components in Tubers, Leaves and Calli Cultures of Three Jerusalem Artichoke Cultivars
}

\author{
Neama Abdalla ${ }^{{ }^{*}}$, Mohamed Ragab ${ }^{2}$, Salah El-Miniawy ${ }^{2}$, Nermeen Arafa ${ }^{1}$, László \\ Kaszás $^{3}$, Zoltán Kovács ${ }^{3}$, Éva Domokos-Szabolcsy ${ }^{3}$ and Hussein Taha ${ }^{1}$ \\ ${ }^{1}$ Plant Biotechnology Department, Genetic Engineering and Biotechnology Research \\ Division, National Research Centre, 33-El-Buhouth St., 12622 Dokki, Cairo, Egypt \\ ${ }^{2}$ Horticulture Department, Faculty of Agriculture, Ain Shams University, 11241 \\ Shoubra El-Kheima, Cairo, Egypt \\ ${ }^{3}$ Agricultural Botany, Plant Physiology and Biotechnology Department, Debrecen \\ University, 138 Böszörményi St., 4032 Debrecen, Hungary
}

\begin{abstract}
D UE to several bioproducts derived from Jerusalem artichoke (JA), it has several ecological and economical benefits in bioenergy production, functional foods and human health. These bio-based multi-products include fructose, inulin, antioxidants, natural fungicides and bio-ethanol. This study included the assessment of some biochemical components of in vitro calli cultures, in vivo tubers and leaves of three JA cultivars and their significant role for human health. Inulin as a functional food ingredient, fructose, protein and polyphenols were selected. The most important findings demonstrated that the crude content in tubers of any studied JA cultivar was 4-5 folds that in calli cultures. The lowest values of fructose among JA fractions were recorded for calli derived from the three studied cultivars. Both calli culutres and leaves of all studied JA cultivars showed the highest crude protein comparing with the tubers. The total soluble phenols were higher in calli cultures of all JA cultivars than which recorded with both of leaves and tubers. This is the first report handles the comparison among calli cultures, tubers and leaves of three JA cultivars in their content of the bioactive compounds. Further investigations are required not only to determine the fractionations of the bioactive compounds but also different approaches of plant biotechnology techniques should be employed to increase the studied bioactive components particularly the inulin and fructose in calli cultures of the investigated JA cultivars.
\end{abstract}

Keywords: Helianthus tuberosus L., Plant biotechnology, Calli cultures, Bioactive compounds, Inulin, Polyphenols, Protein

\section{Introduction}

Jerusalem artichoke (Helianthus tuberosus L.) has a growing body of literatures (Kaszás et al. 2020a) because of its importance in the agricultural, economical, ecological and industrial sectors. It is considered as a promising crop for producing raw materials for foodstuff or functional foods, animal feed and biofuel production as an energy crop in recent years (Lv et al. 2019 and Zhao et al. 2020). It is a perennial crop belonging to the Asteraceae family, which includes the sunflower genus and it is well known as wild sunflower or topinambur or sunchoke (Lv et al. 2019). Jerusalem artichoke had been cultivated during the food crisis in the past, but now it is mainly considered as a "non-food energy crop" or as a biorefinery crop (Johansson et al. 2015) or to be as a source for both the

"Corresponding author: Email address: neama ncr@yahoo.com

Received 8/09/2020; Accepted 4/10/2020

DOI: $10.21608 /$ jenvbs.2020.42184.1106

C2020 National Information and Documentation Center (NIDOC) 
inulin and forage (Lv et al. 2019). This crop has powerful ecological restoration features including a large biomass, rapid growth, low management cost, low water and nutrient requirements and strong adaptability which make its cultivation supporting food security (Kaszás et al. 2020a and Zhao et al. 2020).

Jerusalem artichoke; a tuberous perennial plant; might be cultivated as edible tubers, animal feedstock and folk medicine. JA could be propagated in vivo (seeds, tubers, rhizomes, stem cuttings and slips) or in vitro through tissue culture techniques (Abdalla et al. 2014). The tubers of JA are the main organ for feed and food processing, which have some changes during its development. These changes may require the following periods of weeks to reach to the maturity of tubers: the $9^{\text {th }}$ week for forming creeping stems, the $17^{\text {th }}$ week for forming tubers, the $22^{\text {nd }}$ week for tubers swelling and the $24^{\text {th }}$ week for tubers maturation (Zhao et al. 2020).

The tubers of JA are the main storage organ of this plant, which have a high content of inulin and fructo-oligosaccharide (Kaszás et al. 2020b). This inulin could be stored in the tubers as fructosebased inulin, used as a polysaccharide compared to other common plant species that store carbohydrates as sucrose-based starch (Zhao et al. 2020). The inulin of JA has several health benefits such as reducing diabetes risk, improving the food taste in the human diet, lowering blood sugar and its fat, promoting the absorption of minerals and vitamins, regulating intestinal microbial flora and preventing the obesity as a prebiotic (Green et al. 2020 and Wan et al. 2020). Nowadays, inulin is widely used in several industries particularly the foods and pharmaceutics. In the food sector, inulin may use as a fat replacer, sweetener thickener and water-retaining agent, whereas it could be applied in the pharmaceutics as a drug carrier, stabilizer and auxiliary therapeutic agent for certain diseases (Qiu et al. 2018 and Wan et al. 2020).

It is well established that JA was originated from North America with wide ecological adaptability. The genus of Helianthus is known with a remarkable genetic variability in its genotypes and clones, including about 66 species native to the United States and South East of Eastern and Central Canada. JA can grow in Mediterranean regions under nearly zero applied fertilizers or organic matter or applied pesticides (De Santis and Frangipane, 2018). It is also could be cultivated under different climatic zones due to its tolerance to abiotic stresses, great ecological resiliency and high photosynthetic efficiency (Shao et al. 2019). Many studies have evaluated the potential of JA under different stresses such as drought (Puangbut et al. 2017), waterlogging (Yan et al. 2018) and salinity (Shao et al. 2019; Yue et al. 2020 and Zou et al. 2020). The chemical composition of JA tubers is an important issue, which may differ among cultivars depending on production conditions, harvest periods, postharvest storage and processing methods (Qui et al. 2018).

Human health is the main target that researchers are focusing on it through several agricultural practices or approaches including biofortification (Szarka et al. 2020), and the sustainable plant nutrition (El-Ramady et al. 2020). Based on upon above, this study aimed to assess some biochemical components of three JA cultivars through the in vivo tubers, leaves and in vitro calli culture samples including measurements of (fructose, polyphenols and crude protein) and inulin (in tubers and calli cultures).

\section{Materials and Methods}

This study was carried out on three cultivars of Jerusalem artichoke (i.e., Balady, Fuza and Alba). The three cultivars were selected from three different locations. The tubers of Balady and Fuza were obtained from Giza and Ismailia, respectively in Egypt, whereas the tubers of Alba cultivar were obtained from Debrecen University, Hungary. All collected tubers were cultivated at the Experimental Farm of Faculty of Agriculture, Cairo University, Egypt $\left(30^{\circ} 01^{\prime}\right.$ $\left.\mathrm{N}, 31^{\circ} 12^{\prime} \mathrm{E}\right)$. Stem-derived calli cultures of the three cultivars, which were obtained as described by Abdalla et al. (2019), tubers and leaves of in vivo growing plants of those cultivars were dried in the oven at $45^{\circ} \mathrm{C}$ for three days then ground into powder samples. The biochemical parameters (i.e., polyphenols, crude protein and fructose) were measured in dried samples during 2019 at Department of Agricultural Botany, Plant Physiology and Biotechnology, Debrecen University, Hungary (473 $33^{\prime} \mathrm{N}$; $21^{\circ} 36^{\prime} \mathrm{E}$ ) (Table. 1 \& Fig. A).

Polyphenols content of dried samples of tubers, leaves and calli cultures of the three JA cultivars was determined spectro-photometerically using UV-spectrophotometer (2100 pro, Amersham BioSciences, Amersham, UK) according to Singleton and Rossi (1965).The crude protein content was 
measured in dried samples of tubers, leaves and calli cultures of the three JA cultivars, where the samples were digested into 250-mL Kjeldahl digestion tubes and the Kjeldahl digestion tubes were transferred to a Digestor (VELT, VWRLtd.) and incubated at $350{ }^{\circ} \mathrm{C}$ for $90 \mathrm{~min}$ using sulfuric acid (98\%). The digested samples were used for measuring the total nitrogen $(\mathrm{N})$ content using the titration method described by A.O. A. C. (1990). The crude protein of the samples was calculated using the following equation:

Crude protein $(\%)=$ total $\mathrm{N}$ content $\times 6.25$;
Whereas Fructose content was measured using the instrument of Synergy ${ }^{\mathrm{TM}}$ HTX Multi-Mode Microplate Reader (USA). The measurement of fructose content was carried out using BioVision Fructose Assay Kit colormetrically with UV-Vis absorbance at $570 \mathrm{~nm}$ (Fig. B). While, inulin content was measured in the dried tubers and calli cultures of the three cultivars of JA according to Nguyen et al. (2009) in the Lab of Feed and Food, Agricultural Research Centre, Egypt and reported by Abdalla (2020)

TABLE 1 . The information about samples which were analyzed in the current study

\begin{tabular}{ll}
\hline samples & Important dates for the study scheme \\
\hline In vivo samples & At the end of 2014 and the beginning of 2015: the tubers of studied JA cultivars \\
Tubers of Balady & collected from Giza and Ismailia in Egypt for Balady and Fuza, respectively and \\
Tubers of Fuza & Debrecen in Hungary for Alba cultivar. \\
Tubers of Alba & Furing 2015-2018: the collected tubers were cultivated in Experimental Farm of \\
Leaves of Balady & The cultivated plants of the three cultivars were the source of tubers and leaves \\
Leaves of Fuza & which were taken for chemical analysis \\
Leaves of Alba & Stem-derived calli cultures of the three studied cultivars was obtained by Abdalla \\
In vitro samples & et al. (2019) \\
Callus of Balady & During 2019: all biochemical measurements (except inulin) of in vivo and in vitro \\
Callus of Fuza & samples of studied JA cultivars were assessed at the Department of Agricultural \\
Callus of Alba & Botany, Plant Physiology and Biotechnology, Debrecen University, Hungary
\end{tabular}
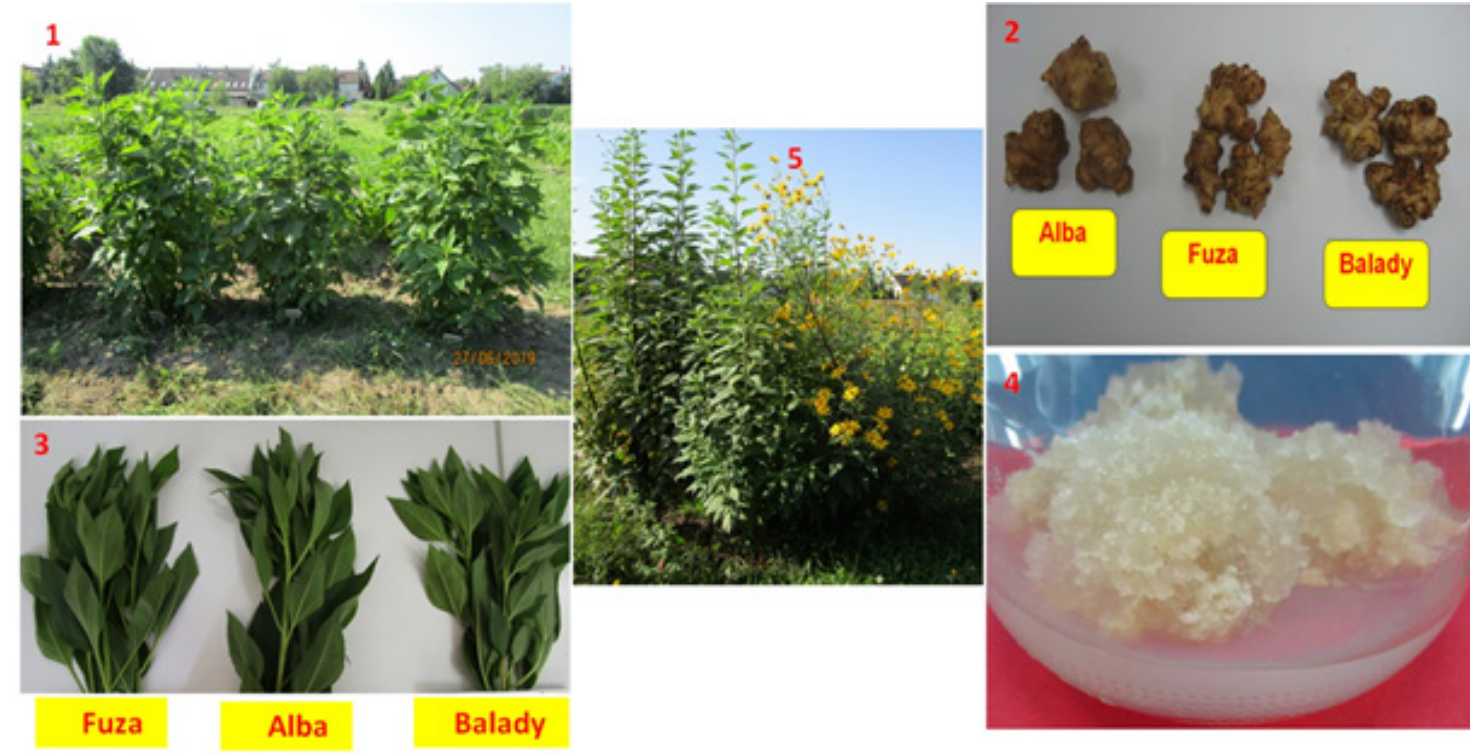

Fig. A. General features of JA plant. Photo (1): the cultivated JA plant at vegetative stage, photo (2): the tubers of each cultivar, photo (3): the leaves of each cultivar, photo (4): the stem derived calli cultures of one of the studied cultivars, photo (5): the cultivated JA plant at flowering stage. Photos $(1,5)$ at Demonstration Garden, Agricultural Botany, Plant Physiology and Biotechnology Dept., Debrecen Uni., Hungary (2019) 


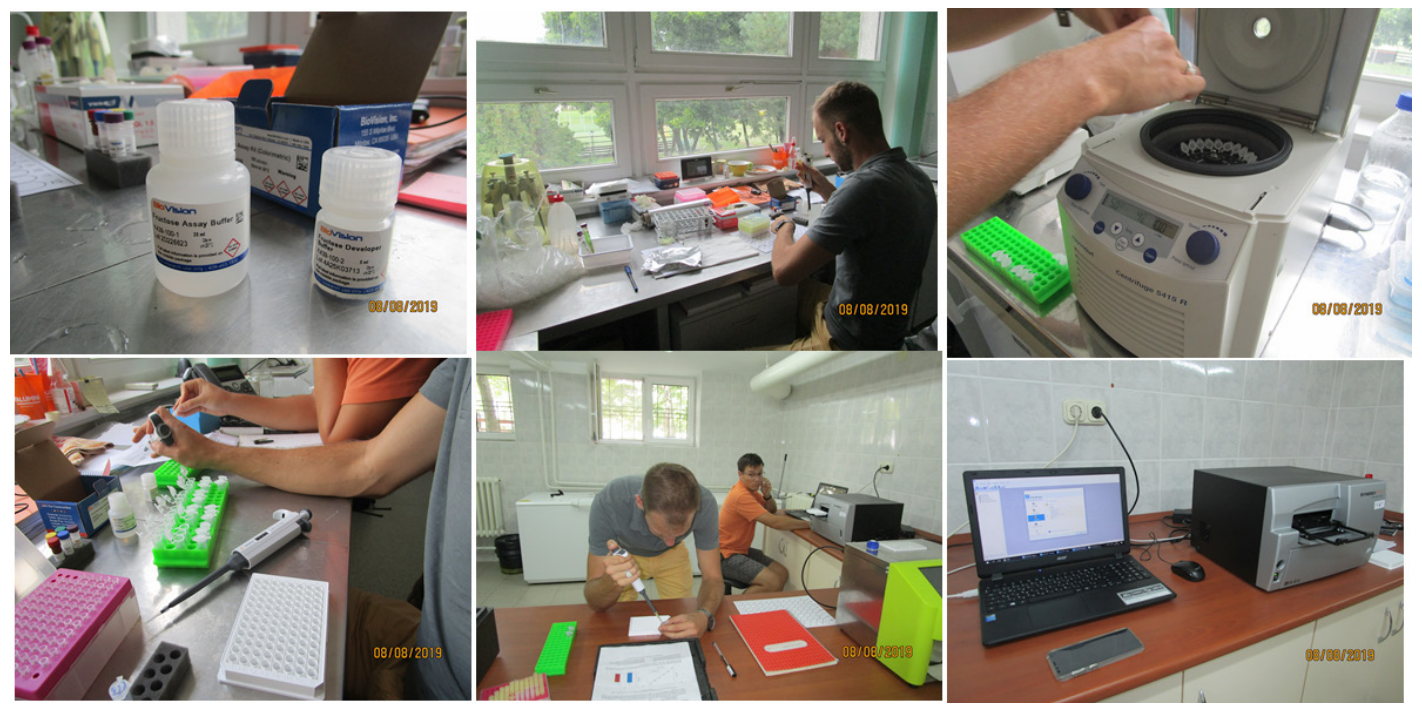

Fig. B. Some steps used during the measurement of fructose in JA using instrument of Synergy ${ }^{\mathrm{TM}}$ HTX MultiMode Microplate Reader at Debrecen University. These steps stared by selecting proper buffers, adding the buffer to samples, then centrifuging and finally measuring the fructose content at $570 \mathrm{~nm}$

We clarify that the quality assurance for obtained results was achieved during the performance of this study by applying the internal and external quality assurance systems at the Central Laboratory of Debrecen University according to MSZ EN ISO 5983-1:2005 (for Total N). The study was designed in completely randomized design in three replicates, Duncan's Multiple Range Test was used for all the obtained data after tabulating to statistically analyze and comparing among means of different fractions (tubers, leaves and calli cultures) of the three cultivars according to Snedecor and Cochran (1990). All statistical analyses were performed using analysis of variance technique by means of Co-STAT computer software package.

\section{Results and Discussion}

\section{Inulin content}

As presented in Table 2, the obtained results clearly showed that there were significant differences among JA cultivars in thier content of inulin in the tubers and Alba was the best. Also, calli cultures of the three cutivars showed up significant differences in thier content of inulin and the highest value recorded for Fuza. On the other hand, the inulin content in tubers of each cultivar represented about 4-5 fold that of its calli cultures.

The most important finding might emphasize that the calli culture of all studied JA cultivars contains a considerable amount of inulin (ranged from 8.62 to $13.09 \%$ of dry weight), whereas, the tubers of JA are the main organ that store inulin, as tubers of different JA cultivars contain inulin more than $46 \%$ of dry weight. This content of inulin in JA calli cultures may open a new field for increasing this amount of inulin using in vitro tools to produce the desirable amounts of inulin for human health on the industrial scale. So, further studies should be done by employment plant biotechnology techniques to enhance the accumulation of inulin in calli cultures of these JA cultivars under investigation using either precursors or elicitors. Besides, hairy root cultures for optimizing inulin production could be initiated from calli cultures or in vitro plantlets of Jerusalem artichoke. Moreover, cell suspention cultures should be established from calli cultures of the studied JA cultivars for maximization the production of inulin. In this context, few literatures have been published where Inulinase activity (an indicator for inulin accumulation) in calli cultures and regenerated shootlets derived from leaf and nodal stem explants of Jerusalem artichoke was determined (Taha et al. 2007). Moreover, a promising protocol for enhancement the accumulation rate of inulin in suspension cultures of Jerusalem artichoke using biotic elicitors was established (Taha et al. 2012).

\section{Fructose content}

The measured fructose content in different JA cultivars and their fractions (tubers, leaves and calli cultures) was tabulated in Table 3 . In general, the fructose content in tubers recorded 
TABLE 2. Inulin (fructo-oligosaccharide) content (\%) of dry weight of tubers and calli cultures of Jerusalem artichoke cultivars

\begin{tabular}{lcc}
\hline Cultivar & Tubers & Calli cultures \\
\hline Balady & $46.18 \mathrm{c}$ & $8.62 \mathrm{~b}$ \\
Fuza & $47.83 \mathrm{~b}$ & $13.09 \mathrm{a}$ \\
Alba & $49.72 \mathrm{a}$ & $10.58 \mathrm{ab}$ \\
F-test & $* *$ & $* *$ \\
\hline
\end{tabular}

Each value was the average of 3 replicates. Values followed by different letters in the same column were significantly differed by Duncan's test at 0.05 level

TABLE 3. Fructose content $\left(\mathrm{mg} \mathrm{l}^{-1}\right)$ in tubers, leaves and calli cultures of $\mathbf{J A}$ cultivars

\begin{tabular}{cccc}
\hline & \multicolumn{3}{c}{ Fructose content $\left(\mathrm{mg} \mathrm{l}^{-\mathbf{1}}\right)$} \\
\cline { 2 - 4 } Cultivar & Tubers & Leaves & Calli cultures \\
\hline Balady & $34.50 \mathrm{c}$ & ------ & $11.94 \mathrm{a}$ \\
Fuza & $74.99 \mathrm{~b}$ & $62.20 \mathrm{a}$ & ------ \\
Alba & $106.4 \mathrm{a}$ & $46.65 \mathrm{~b}$ & $9.38 \mathrm{~b}$ \\
F-test & $* *$ & $* *$ & $* *$ \\
\hline
\end{tabular}

Each value was the average of 3 replicates. Values followed by different letters in the same column were significantly differed by Duncan's test at 0.05 level

Note: the dashed lines (-----) means that samples were missed

the highest values compared to that of the leaves and calli cultures in each cultivar. The highest fructose content belonged to the tuber of Alba cultivar $\left(106.4 \mathrm{mg} \mathrm{l}^{-1}\right)$. The most striking result to emerge from the data in Table 3 is that the fructose content in calli cultures of the three studied cultivars recorded the lowest values of fructose among JA fractions, hence, there is an urgent need to work on increasing the fructose content in JA calli cultures in the future by plant biotechnology techniques. The most attracting attention from the obtained data was the very high content of fructose in tubers of Alba cultivar.

The promising result in this work represented in possessing the calli cultures of Balady and Alba cultivars a considerable amount of fructose (11.94 and 9.38, respectively), although this amount in tubers and leaves are much higher than in calli cultures. This distinguished finding may encourage us to work on discover a new in vitro technique to increase the harvested fructose from calli cultures of JA for human health.

After starch and sucrose, fructose represents the third largest storage carbohydrate in plant species. The plants, which contain fructose, are mostly growing in cold temperate zones including Asteraceae, Gramineae and Liliaceae families. Plant fructans (polysaccharides) have an important role in processed foods, which could maintain human health. These fructans also are optimal sweetener and nutrient for diabetes and hypertension patients as well as alternatives for fats in foods such as ice cream, yogurt, and jelly pudding (Yang et al. 2019).

Fructose as a keto-hexose or isomer of glucose, is metabolized almost completely in the liver of humans unlike glucose (Qi and Tester 2019). Fructose could be produced to be involving inulin, which is a fructan and is a potential source of inulo-oligosaccharides and fructose for using in pharmaceuticals and foods. Fructose is characterized as a recommended for diabetics, an alternative sweetener to sucrose, the sweetest natural sugars and has a low glycemic index compared to sucrose (Prangviset et al. 2018). Fructose could be used for making capsule formulations and solutions for injections and infusions as well as for the innumerable pharmaceutical industries because of its wide physiological roles in human body (Singh et al. 2018). 


\section{Polyphenols content}

The obtained results showed significant differences in the content of polyphenols among the JA cultivars for each fraction (Table 4). The calli cultures of the three JA cultivars contained the highest polyphenols followed by tubers then leaves, except Alba cultivar which was higher in leaves than tubers. On the calli cultures level, the polyphenols of Alba cultivar had the highest value $\left(56.40 \mu \mathrm{g} \mathrm{g}^{-1}\right)$, whereas the lowest one belonged Balady cultivar $\left(49.22 \mu \mathrm{g} \mathrm{g}^{-1}\right)$.

It is noted that all JA fractions including tubers, leaves and calli cultures of the three cultivars have a considerable amount of polyphenols ranged from 33.19 to $56.40 \mu \mathrm{g} \mathrm{g}^{-1}$. The highest values of polyphenols were recorded by calli cultures for all studied JA cultivars. This result might give us a great chance to produce the phenolic compounds via plant biotechnology for different purposes.

Phenolic compounds are considered the most distinguished group of bioactive compounds in different plant sources. It is reported that JA is a source of phenolic compounds, which mainly are phenolic acids (Rashmi and Negi, 2020). Phenolic acids also are very common compounds found in plant-derived foods as secondary metabolites, which have many potential health benefits. These phenolic compounds in JA tubers are considered as powerful antioxidants, antiviral, antibacterial, anticarcinogenic, anti-inflammatory and vasodilatory actions (Amarowicz et al. 2020). Many phenolics in plants could be used as functional additives in foods because of their role in delaying the microbial growth, inhibition of lipid oxidation and then prolong the shelf-life of foods (Rashmi and Negi, 2020).

Phenolic compounds in plants, more than 8000 structures are known, represent an important secondary metabolites group, which have biological roles in promoting the human health. These phenolic compounds also include the phenolic metabolites or polyphenols, which classified into flavonoid (e.g., flavones, flavanones, flavonols, and anthocyanidins) and non-flavonoid compounds (e.g., phenolic acids, lignans, tannins and lignins). These polyphenols have an effective role in the natural medicine as antioxidant, antimicrobial action and antiinflammatory (Działo et al. 2016).

\section{Crude protein content}

In the current study, the crude protein content of JA fractions in the three studied JA cultivars was listed in Table 5. The crude protein in both leaves and calli cultures of JA was around 3 folds that in tubers and they are nearly similar. There were significant differences among cultivars in crude protein content for each fraction alone. On the level of both JA fraction and cultivar, the maximum crude protein content was belonged to calli cultures of Alba (25.84\%), whereas the lowest one was recorded for the tubers of Alba cultivar $(7.56 \%)$. These results confirmed that the leaves of JA are the main organ of the plant containing proteins compared to tubers. This explains why the green biomass of JA is used as green forage for animal feeding, while the tubers for human nutrition as a source of inulin and fructose. The result reported that the highest values of crude protein were slightly higher in case of leaves and calli cultures than tubers giving a very good impression on the possibility to produce enough amounts of proteins from calli cultures through plant biotechnology techniques.

Proteins are considered an essential component in the daily diet of human, which represent a main source of the amino acids. The ingestion of amino acids may stimulate the postprandial muscle protein synthesis and physical activity. The human body needs every day about $80 \mathrm{~g}$ per $100 \mathrm{~kg}^{-1}$ of body weight as a sufficient supply of

TABLE 4. Polyphenols content $\left(\mu \mathrm{g} \mathrm{g}^{-1}\right)$ in tubers, leaves and calli cultures of JA cultivars

\begin{tabular}{lccc}
\hline & \multicolumn{3}{c}{ Polyphenols $\left(\boldsymbol{\mu g} \mathbf{g ~}^{-1}\right)$} \\
\cline { 2 - 4 } Cultivar & Tubers & Leaves & Calli cultures \\
\hline Balady & $43.88 \mathrm{a}$ & $39.78 \mathrm{a}$ & $49.22 \mathrm{~b}$ \\
Fuza & $46.85 \mathrm{a}$ & $33.19 \mathrm{~b}$ & $51.04 \mathrm{~b}$ \\
Alba & $37.39 \mathrm{~b}$ & $40.12 \mathrm{a}$ & $56.40 \mathrm{a}$ \\
F-test & $*$ & $* *$ & $* *$ \\
\hline
\end{tabular}

Each value was the average of 3 replicates. Values followed by different letters in the same column were significantly differed by Duncan's test at 0.05 level 
TABLE 5. Crude protein content $(\%)$ in tubers, leaves and calli cultures of JA cultivars

\begin{tabular}{|c|c|c|c|}
\hline \multirow[b]{2}{*}{ Cultivar } & \multicolumn{3}{|c|}{ Total crude protein content (\%) } \\
\hline & Tubers & Leaves & Calli cultures \\
\hline Balady & $8.43 \mathrm{a}$ & $23.64 b$ & $23.70 \mathrm{c}$ \\
\hline Fuza & $8.56 \mathrm{a}$ & $24.82 \mathrm{a}$ & $24.33 b$ \\
\hline Alba & $7.56 b$ & $22.18 \mathrm{c}$ & $25.84 \mathrm{a}$ \\
\hline F-test & $* *$ & $* *$ & $* *$ \\
\hline
\end{tabular}

Each value was the average of 3 replicates to compare between means of the same column. Values followed by the same letters were not significantly different by Duncan's test at 0.05 level

amino acids for healthy adults. It is well stated that "the dietary protein is an essential nutrient required to preserve muscle mass as well as vital function and regulates whole-body metabolic health". The main sources of plant proteins include oil plants, leguminous plants and pseudo-cereals like quinoa and amaranth. The protein derived from soy bean is the only plant-based protein source, which has been extensively investigated for human health (Weindl et al. 2020). Although JA is mainly cultivated for inulin production from their tubers, it could produce significant amounts of leaf protein concenrtate and economic bioactive phytochemicals from freshaerial biomass (Kaszás et al. 2020a).

Globally, there is an urgent need to address the health problems caused by malnutrition. It is well known that proteins are considered essential macro-nutrients for human nutrition. The quality of nutritional protein mainly depends on its bioavailability and digestibility, the profile of amino acids and processing effects (Sá et al. 2019). There is an increasing global trend for plant-based diets due to plant proteins are versatile alternative replacing animal source in human nutrition, as well as functional ingredients for product formulation (Sá et al. 2020). It is reported that proteins content in JA tubers might reach up to $10 \%$ of dry matter, whereas the content of free sugars (e.g., glucose, sucrose and fructose) is much lower compared to protein content and rarely exceeds $6-8 \%$ of dry matter (Nizioł-Łukaszewska et al. 2018).

\section{Conclusion}

Jerusalem artichoke is considered a promising crop for producing non-food raw materials or bio-based multi-products, which include inulin, fructose, antioxidant and bio-ethanol. This crop has unique advantages being strong adaptability to many environmental conditions, a biorefinery and a prebiotic-rich crop. The cultivars and fractions of this crop may differ in their biochemical properties as investigated in the current study. Three cultivars of JA have been selected from three locations, which collected and cultivated in
Giza for three years. The most important findings of this study might emphasize on the biochemical composition of the studied JA cultivars particularly in vitro calli cultures as a first report. These bioactive compounds including inulin, fructose, protein and polyphenols are considered very important for human health. The high content of polyphenols in calli cultures of all studied JA cultivars and the considerable amounts of both inulin and fructose in calli cultures also might be exploited in producing these vital compounds at the industrial level in the future through plant biotechnology techniques. This research also may suggest that the calli cultures of JA can depend on it in supplying our demand from inulin, fructose, protein and phenolic compounds in the future.

\section{Author Contributions}

This study was designed and implemented by Neama Abdalla under supervision of Prof. Dr Mohamed Emam Ragab, Prof. Dr Hussein Sayed Taha and Dr. Nermeen Arafa. Hungarian authors kindly provided us with the needed chemicals and helped us to achieve all studied analyses as well. The authors contributed in writing the paper, interpreting information presented and have agreed to the version of the manuscript.

\section{Conflicts of Interest}

The authors declare that there is no conflict of interest.

\section{Acknowledgement}

The authors thank Dr. Megahed Amer (Soil, Water and Environment Institute, ARC, Egypt) for his great help in statistical analysis of data. Authors also appreciate the great help from Prof. Dr. Said Shehata (Vegetable Crops Dept., Faculty of Agriculture, Cairo University, Egypt) for allowing us cultivating the three cutivars of JA at the Experimental Farm, Faculty of Agriculture, Cairo University in Giza during the period from 2015 to 2018. 


\section{Refereneces}

A.O.A.C (1990). Official method of analysis of the A.O.A.C (W. Hortwitz) $13^{\text {th }}$ edition Washington D.C. P. 858.

Abdalla N (2020). Micropropagation of Jerusalem artichoke (Helianthus tuberosus L.) Plant. Ph. D. Thesis, Horticulture Dept., Faculty of Agriculture, Ain Shams University, Egypt.

Abdalla N, Domokos-Szabolcsy É, El-Ramady H, Hodossi S, Fári M, Ragab M, Taha H (2014). Jerusalem artichoke (Helianthus tuberosus L.): A review of in vivo and in vitro propagation. International Journal of Horticultural Science, 20 (3-4): 131-136.

Abdalla N, Ragab ME, El-Miniawy SM, Taha HS (2019). Enhancement of calli growth in three cultivars of Jerusalem artichoke. Arab Univ. J. Agric. Sci., Ain Shams Univ., Cairo, Egypt, 27 (9): 1937-1945.

Amarowicz R, Cwalina-Ambroziak B, Janiak MA, Bogucka B (2020) Effect of N Fertilization on the Content of Phenolic Compounds in Jerusalem Artichoke (Helianthus tuberosus L.) Tubers and Their Antioxidant Capacity. Agronomy 10, 1215, doi:10.3390/agronomy 10081215

De Santis D, Frangipane MT (2018) Evaluation of chemical composition and sensory profile in Jerusalem artichoke (Helianthus tuberosus L.) tubers: The effect of clones and cooking conditions. International Journal of Gastronomy and Food Science 11: 25-30. https://doi.org/10.1016/j. ijgfs.2017.11.001

Działo M, Mierziak J, Korzun U, PreisnerM, Szopa J, Kulma A (2016) The Potential of Plant Phenolics in Prevention and Therapy of Skin Disorders. Int J Mol Sci. 17 (2): 160. doi: 10.3390/ijms 17020160

El-Ramady H, Olle M, Eichler-Löbermann B, Schnug E(2020). Towards A New Concept of Sustainable Plant Nutrition. Env. Biodiv. Soil Security 4 (4): 17. DOI: $10.21608 /$ jenvbs.2020.21970.1080

Green, M, Arora K, Prakash S (2020) Microbial Medicine: Prebiotic and Probiotic Functional Foods to Target Obesity and Metabolic Syndrome. Int J Mol Sci. 21 (8): 2890. doi: 10.3390/ijms21082890

Johansson E, Prade T, Angelidaki I, Svensson S-E, Newson WR, Gunnarsson IB, Hovmalm HP (2015). Economically Viable Components from Jerusalem Artichoke (Helianthus tuberosus L.) in a Biorefinery Concept. Int J Mol Sci. 16 (4): 8997-
9016. doi: 10.3390/ijms16048997

Kaszás, L, Alshaal T, El-Ramady H, Kovács Z, Koroknai J, Elhawat N, Nagy É, Cziáky Z, Fári M, Domokos-Szabolcsy, É (2020b) Identification of Bioactive Phytochemicals in Leaf Protein Concentrate of Jerusalem Artichoke (Helianthus tuberosus L.). Plants (Basel) 9 (7): 889. doi: 10.3390/plants 9070889

Kaszás, L, Alshaal T, Kovács Z, Koroknai J, Elhawat N, Nagy É, Cziáky Z, El-Ramady H, Fári M, Domokos-Szabolcsy, É (2020a) Refining highquality leaf protein and valuable co-products fromgreen biomass of Jerusalem artichoke (Helianthus tuberosus L.) for sustainable protein supply, Biomass Conversion and Biorefinery, https://doi.org/10.1007/s13399-020-00696-z

Kays SJ; Nottingham SF (2008) Chemical Composition and Inulin Chemistry. In: Kays and Nottingham (authors), Biology and Chemistry of Jerusalem artichoke: Helianthus tuberosus L. pp: 53-96. CRC Press, Boca Raton, Taylor \& Francis Group, LLC

Lv S, Wang R, Xiao Y, Li F, Mu Y, Lu Y, Gao W, Yang B, Kou Y, Zeng J, Zhao C (2019). Growth, yield formation, and inulin performance of a non-food energy crop, Jerusalem artichoke (Helianthus tuberosus L.), in a semi-arid area of China. Industrial Crops and Products, 134: 71-79. doi:10.1016/j.indcrop.2019.03.064

Nguyen SK, Sophonputtanaphoca S, Kim E, Penner MH (2009). Hydrolytic methods for the quantification of fructose equivalents in herbaceous biomass. Appl Biochem Biotechnol, 158 (2):352-361. doi: 10.1007/s12010-009-8596-x

Nizioł-Łukaszewska Z, Furman-Toczek D, ZagórskaDziok M (2018). Antioxidant activity and cytotoxicity of Jerusalem artichoke tubers and leaves extract on $\mathrm{HaCaT}$ and $\mathrm{BJ}$ fibroblast cells. Lipids Health Dis. 17: 280. doi: 10.1186/s12944018-0929-8

Prangviset K, Songpim M, Yodsuwan N, Wannawilai S, Dejsungkranont M, Changlek P, Sirisansaneeyakul S (2019) Fructose production from Jerusalem artichoke using mixed inulinases. Agriculture and Natural Resources. doi:10.1016/j.anres.2018.08.001

Puangbut, D, Jogloy S, Vorasoot N (2017). Association of photosynthetic traits with water use efficiency and SPAD chlorophyll meter reading of Jerusalem artichoke under drought conditions. Agricultural Water Management 188: 29-35. http://dx.doi. org/10.1 
Qi X, Tester RF (2019) Fructose, galactose and glucose $\mathrm{e}$ in health and disease. Clinical Nutrition ESPEN 33:18-28. https://doi.org/10.1016/j.clnesp.2019.07.004

Qiu Y, Lei P, Zhang Y, Sha Y, Zhan Y, Xu Z, Li S, Xu H, Ouyang P (2018). Recent advances in bio-based multi-products of agricultural Jerusalem artichoke resources. Biotechnol Biofuels, 11: 151. doi: 10.1186/s13068-018-1152-6

Rashmi HB, Negi PS (2020). Phenolic acids from vegetables: A review on processing stability and health benefits. Food Research International, 109298. doi:10.1016/j.foodres.2020.109298

Sá AGA, Moreno YMF, Carciofi BAM (2019). Food processing for the improvement of plant proteins digestibility. Critical Reviews in Food Science and Nutrition, 1-20. https://doi.org/10.1080/10408398. $2019.16882490(0)$

Sá AGA, Moreno YMF, Carciofi BAM (2020). Plant proteins as high-quality nutritional source for human diet. Trends in Food Science \& Technology. doi:10.1016/j.tifs.2020.01.011

Shao, T, Gu X, Zhu T, Pan X, Zhu Y, Long X, Shao H, Liu M, Rengel Z (2019). Industrial crop Jerusalem artichoke restored coastal saline soil quality by reducing salt and increasing diversity of bacterial community. Applied Soil Ecology 138: 195-206. https://doi.org/10.1016/j.apsoil.2019.03.003

Singh RS, Chauhan K, Pandey A, Larroche C (2018). Biocatalytic strategies for the production of high fructose syrup from inulin. Bioresource Technology 260: 395-403. https://doi.org/10.1016/j. biortech.2018.03.127

Singleton VL, Rossi JA (1965) Colometry of total phenolics with phosphomolybdic-phosphotunistic acid reagents. Am. J. Enol. Vitic. 16: 144-158.

Snedecor GW, Cochran WG (1990) Statistical Methods. The $8^{\text {th }}$ edition, Iowa State Univ. Press, Ames.

Szarka V, Jokai Z, El-RamadyH, Abdalla N, Kaszás L, Domokos-SzabolcsyÉ (2020). Biofortification of Stevia rebaudiana (Bert.) Plant with Selenium. Env. Biodiv. Soil Security 4 (4):19 - 31. DOI :10.21608/ jenvbs.2020.25902.1085

Taha HS, Abd El-Kawy AM, Abd El-Kareem Fathalla M (2012) A new approach for achievement of inulin accumulation in suspension cultures of Jerusalem artichoke (Helianthus tuberosus L.) using biotic elicitors. Journal of Genetic Engineering and Biotechnology, 10 (1): 33-38. https://doi. org/10.1016/j.jgeb.2012.02.002
Taha HS, El-Sawy AM, Bekheet SA (2007) In Vitro Studies on Jerusalem artichoke (Helianthus tuberosus L.) and Enhancement of Inulin Production. J. of Applied Sci. Research, 3 (9), 853-858.

Wan X, Guo H, Liang Y, Zhou C, Liu Z, Li K, Niu F, Zhai X, Wang L (2020). The physiological functions and pharmaceutical applications of inulin: A review. Carbohydrate Polymers 246, 116589. https://doi. org/10.1016/j.carbpol.2020.116589

Weindl I, Ost M, Wiedmer P, Schreiner M, Neugart S, Klopsch R, Kühnhold H, Kloas W, Henkel IM, Schlüter O, Bußler S, Bellingrath-Kimura SD, Ma H, Grune T, Rolinsk S, Klaus S (2020) Sustainable food protein supply reconciling human and ecosystem health: A Leibniz Position. Global Food Security, 25, 100367. doi:10.1016/j. gfs.2020.100367

Yan K, Zhao S, Cui M, Han G, Wen P (2018). Vulnerability of photosynthesis and photosystem I in Jerusalem artichoke (Helianthus tuberosus L.) exposed to waterlogging. Plant Physiology and Biochemistry 125: 239-246. https://doi. org/10.1016/j.plaphy.2018.02.017

Yang S, Sun X, Jiang X, Wang L, Tian J, Li L, Zhao M, Zhong Q (2019). Characterization of the Tibet plateau Jerusalem artichoke (Helianthus tuberosus L.) transcriptome by de novo assembly to discover genes associated with fructan synthesis and SSR analysis. Hereditas, 156: 9. doi: 10.1186/s41065019-0086-8

Yue, Y, Shao T, Long X, He T, Gao X, Zhou Z, Liu Z, Rengel Z (2020). Microbiome structure and function in rhizosphere of Jerusalem artichoke grown in saline land. Science of the Total Environment 724, 138259. https://doi. org/10.1016/j.scitotenv.2020.138259

Zhao M, Zhong Q, Tianc M, Hanc R, Ren Y (2020) Comparative transcriptome analysis reveals differentially expressed genes associated with the development of Jerusalem artichoke tuber (Helianthus tuberosus L.). Industrial Crops \& Products 151, 112455. https://doi.org/10.1016/j. indcrop.2020.112455

Zou H-X, Zhao D, Wen H, Li N, Qian W, Yan X (2020) Salt stress induced differential metabolic responses in the sprouting tubers of Jerusalem artichoke (Helianthus tuberosus L.). PLoS One 15 (6), doi: 10.1371/journal.pone.0235415. 